\title{
Precision Medicine in Osteosarcoma: MATCH Trial and Beyond
}

\author{
Elisa Tirtei ${ }^{1,2, *(\mathbb{D})}$, Anna Campello ${ }^{1}$, Sebastian D. Asaftei ${ }^{1}\left(\mathbb{D}\right.$, Katia Mareschi $^{1,2} \mathbb{D}^{\mathbb{D}}$, Matteo Cereda ${ }^{3,4}$ (D) \\ and Franca Fagioli 1,2
}

check for

updates

Citation: Tirtei, E.; Campello, A.; Asaftei, S.D.; Mareschi, K.; Cereda, M.; Fagioli, F. Precision Medicine in Osteosarcoma: MATCH Trial and Beyond. Cells 2021, 10, 281. https:// doi.org/10.3390/cells10020281

Academic Editor: Annalisa Santucci Received: 30 December 2020

Accepted: 26 January 2021

Published: 31 January 2021

Publisher's Note: MDPI stays neutral with regard to jurisdictional claims in published maps and institutional affiliations.

Copyright: (c) 2021 by the authors. Licensee MDPI, Basel, Switzerland. This article is an open access article distributed under the terms and conditions of the Creative Commons Attribution (CC BY) license (https:/ / creativecommons.org/licenses/by/ $4.0 /)$.
1 Paediatric Onco-Haematology Division, Regina Margherita Children's Hospital, City of Health and Science of Turin, 10126 Turin, Italy; campello.anna@gmail.com (A.C.); sebastiandorin.asaftei@unito.it (S.D.A.); katia.mareschi@unito.it (K.M.); franca.fagioli@unito.it (F.F.)

2 Department of Public Health and Paediatrics, The University of Turin, Piazza Polonia 94, 10126 Turin, Italy

3 Cancer Genomics and Bioinformatics Unit, IIGM-Italian Institute for Genomic Medicine, c/o IRCCS, Str. Prov.le 142, km 3.95, 10060 Candiolo (TO), Italy; matteo.cereda@iigm.it

4 Candiolo Cancer Institute, FPO_IRCCS, Str. Prov.le 142, km 3.95, 10060 Candiolo (TO), Italy

* Correspondence: etirtei@cittadellasalute.to.it

\begin{abstract}
Osteosarcoma (OS) is a rare bone malignant tumour with a poor prognosis in the case of recurrence. So far, there is no agreement on the best systemic therapy for relapsed OS. The availability of next generation sequencing techniques has recently revolutionized clinical research. The sequencing of the tumour and its matched normal counterpart has the potential to reveal a wide landscape of genetic alterations with significant implications for clinical practice. The knowledge that the genomic profile of a patient's tumour can be precisely mapped and matched to a targeted therapy in real time has improved the development of precision medicine trials (PMTs). PMTs aiming at determining the effectiveness of targeted therapies could be advantageous for patients with a tumour refractory to standard therapies. Development of PMTs for relapsed OS is largely encouraging and is in its initial phase. Assessing OS features, such as its rarity, its age distribution, the technical issues related to the bone tissue origin, and its complex genomic landscape, represents a real challenge for PMTs development. In this light, a multidisciplinary approach is required to fully exploit the potential of precision medicine for OS patients.
\end{abstract}

Keywords: osteosarcoma; precision medicine; next generation sequencing; target-therapy; clinical trials

\section{Introduction}

Osteosarcoma (OS) is a rare mesenchymal tumour [1] and the most common primary malignant bone tumour in adolescents and young adults [2]. Despite the innovations in molecular medicine in recent decades, there has been little progress in the treatment of OS for over 30 years [3]. When the disease is localized, the surgical resection of the primary tumour and multiagent chemotherapy (e.g., high dose methotrexate, adriamycin, and cisplatin with or without ifosfamide) allows for a cure rate of $60-70 \%[1,2,4]$. When the disease presents metastases by the time of diagnosis or in the case of relapsed disease, the prognosis for the patient is poor, and the survival rate is lower than $30 \%$ at 5 years $[1,2,4,5]$.

Despite the consensus on the first line treatment of patients with systemic regimens, when recurrence or progression occurs, there is no international agreement on the best therapy for OS patients [6]. With the exception of the benefits of a surgical complete remission (second or subsequent) [4-6], there continues to be an ongoing debate regarding the efficacy of systemic treatments [4-6] and there is a lack of efficient treatment options for patients with advanced and relapsed OS.

The availability of Next Generation Sequencing (NGS) techniques has completely revolutionized clinical research, as well as basic and applied medicine over the last decade [7]. NGS is a high-throughput sequencing technology that is able to precisely map the entire genome of an individual in a few hours with a limited cost [8]. NGS approaches include 
whole genome sequencing, exome sequencing, transcriptome sequencing, and RNA sequencing [8,9]. These methodologies have facilitated the analysis of genomic profiles in cancer patients improving our understanding of the disease $[7,9]$. The tumour sequencing and its matched normal counterpart has the potential to reveal a range of genetic alterations with significant implications for clinical practice in terms of diagnosis, prognosis and subsequent treatment choices [10]. Indeed, NGS allows the identification of tumour specific aberrations with the potential either to discover new prognostic biomarkers or to offer potential information for new personalized treatments, thus improving the precision medicine concept especially for patients with a relapsed/refractory disease $[7,10]$.

The development of precision medicine trials (PMTs) has improved as a result of the knowledge that the genomic profile of a patient's tumour can be precisely mapped and matched, when possible, to a targeted therapy in real time [3]. Initially, PMTs were most common for adult malignancies, especially for the most frequent neoplasms. Thereafter, there was a gradual interest in expanding this personalized approach to rare tumours such as paediatric tumours, including OS [3,11].

So far, standard clinical trial approaches for relapsed or advanced OS patients showed a lack of efficacy $[1,2,6]$. The identification of specific genomic targets for OS patients is essential for better stratification of the patients enrolled in future matched clinical trials [12].

It is now widely accepted that OS patients may benefit from a deep comprehensive molecular genomic sequencing approach $[3,13]$. Nevertheless, this kind of treatment approach is in its infancy, and there are several obstacles to overcome for OS patients as described below.

\section{Oncological Precision Medicine Trials}

Several oncology studies have evaluated the feasibility and use of genomic-driven precision medicine in tumours in recent years.

Molecular Analysis for Therapy CHoice (MATCH) is a precision medicine treatment clinical trial for adult and paediatric patients supported by the National Cancer Institute (NCI) and by the Children's Oncology Group (COG). The trial has an umbrella design with treatment rules based on the presence of a molecular aberration $[11,14,15]$. This study seeks to determine the response rate in adult and paediatric patients with advanced and relapsed solid tumours harbouring genomic alterations that can be treated with available drugs [11]. Following the same principles, further PMTs have been established along the same lines, including some for paediatric patients (Table 1).

Table 1. Published data of recent genomic programs including patients with OS.

\begin{tabular}{|c|c|c|c|c|c|c|}
\hline Trial Title & Inclusion Criteria & $\begin{array}{l}\mathbf{N}^{\circ} \text { Patients En- } \\
\text { rolled/Analysed }\end{array}$ & $\begin{array}{l}\mathbf{N}^{\circ} \text { Enrolled } \\
\text { Patients with } \\
\text { OS }\end{array}$ & $\begin{array}{c}\mathbf{N}^{\circ} \text { Patients with } \\
\text { One or More } \\
\text { Actionable } \\
\text { Alteration }\end{array}$ & $\begin{array}{c}\mathbf{N}^{\circ} \text { Patients } \\
\text { Treated with a } \\
\text { Matched Therapy } \\
\text { Based on Genomic } \\
\text { Data }\end{array}$ & Ref. \\
\hline $\begin{array}{c}\text { Peds- } \\
\text { MiOncoSeq }\end{array}$ & $\begin{array}{c}\mathrm{R} / \mathrm{R} \text { tumours or rare } \\
\text { tumours } \\
\text { age: } \leq 22 \text { yrs }\end{array}$ & $102 / 91$ & $\begin{array}{l}29 \text { patients with } \\
\text { sarcoma } \\
\text { (unspecified) }\end{array}$ & 42 & 15 & [16] \\
\hline INFORM & $\begin{array}{l}\mathrm{R} / \mathrm{R} \text { solid tumours } \\
\text { age: }<40 \mathrm{yrs}\end{array}$ & $57 / 52$ & 4 OS & $39 *$ & 10 & [17] \\
\hline $\begin{array}{c}\text { INFORM } \\
\text { update } 2020\end{array}$ & $\begin{array}{l}\mathrm{R} / \mathrm{R} \text { solid tumours } \\
\text { age: }<40 \mathrm{yrs}\end{array}$ & $1300 / 525$ & Not reported & $\begin{array}{c}444 \\
\text { (120 pts with very } \\
\text { high or high } \\
\text { priority target) }\end{array}$ & 149 & [18] \\
\hline MOSCATO-01 & $\begin{array}{l}\mathrm{R} / \mathrm{R} \text { solid tumours } \\
\text { age: }<25 \mathrm{yrs}\end{array}$ & $73 / 69$ & $4 \mathrm{OS}$ & 42 & 14 & [19] \\
\hline BASIC3 & $\begin{array}{l}\text { paediatric tumours } \\
\text { age: } \leq 18 \text { yrs }\end{array}$ & $150 / 121$ & $4 \mathrm{OS}$ & 33 & Not reported & [10] \\
\hline
\end{tabular}


Table 1. Cont.

\begin{tabular}{|c|c|c|c|c|c|c|}
\hline Trial Title & Inclusion Criteria & $\begin{array}{l}\mathrm{N}^{\circ} \text { Patients En- } \\
\text { rolled/Analysed }\end{array}$ & $\begin{array}{l}\mathrm{N}^{\circ} \text { Enrolled } \\
\text { Patients with } \\
\text { OS }\end{array}$ & $\begin{array}{c}\mathbf{N}^{\circ} \text { Patients with } \\
\text { One or More } \\
\text { Actionable } \\
\text { Alteration }\end{array}$ & $\begin{array}{c}\mathbf{N}^{\circ} \text { Patients } \\
\text { Treated with a } \\
\text { Matched Therapy } \\
\text { Based on Genomic } \\
\text { Data }\end{array}$ & Ref. \\
\hline PIPSeq & $\begin{array}{l}\text { high-risk tumours } \\
\text { age: } \leq 26 \text { yrs }\end{array}$ & $107 / 101$ & $\begin{array}{l}6 \text { OS }+5 \text { other } \\
\text { sarcoma not } \\
\text { more defined }\end{array}$ & 38 & 6 & [20] \\
\hline iCat & $\begin{array}{l}\mathrm{R} / \mathrm{R} \text { high-risk } \\
\text { non-CNS solid } \\
\text { tumours } \\
\text { age: } \leq 30 \text { yrs }\end{array}$ & $101 / 89$ & $11 \mathrm{OS}$ & 31 & 3 & [21] \\
\hline $\begin{array}{l}\text { ClinOmics } \\
\text { Program }\end{array}$ & $\begin{array}{l}\text { non CNS solid } \\
\text { tumours } \\
\text { age: } \leq 25 \text { yrs }\end{array}$ & $64 / 57$ & $4 \mathrm{OS}$ & 30 & Not reported $* *$ & [22] \\
\hline MBB & $\begin{array}{l}\text { High risk or } \mathrm{R} / \mathrm{R} \\
\text { solid tumors } \\
\text { age: } \leq 22 \text { yrs }\end{array}$ & $60 / 58$ & $4 \mathrm{OS}$ & 23 & 6 & [23] \\
\hline TRICEPS & $\begin{array}{c}\mathrm{R} / \mathrm{R} \text { or hard-to-treat } \\
\text { tumours } \\
\text { age: } \leq 22 \text { yrs }\end{array}$ & $84 / 62$ & $7 \mathrm{OS}$ & 47 & 9 & {$[24]$} \\
\hline $\begin{array}{l}\text { MD Anderson } \\
\text { Program }\end{array}$ & $\begin{array}{l}\mathrm{R} / \mathrm{R} \text { sarcoma } \\
\text { age: } 8-76 \text { yrs }\end{array}$ & $102 / 102$ & 11 OS & 95 & 14 (only 1 OS pt) & [25] \\
\hline $\begin{array}{c}\text { NCI-MATCH } \\
\text { Trial }\end{array}$ & $\begin{array}{c}\mathrm{R} / \mathrm{R} \text { solid tumour, } \\
\mathrm{R} / \mathrm{R} \text { lymphoma, } \mathrm{R} / \mathrm{R} \\
\text { myeloma } \\
\text { age: } \geq 18 \text { yrs }\end{array}$ & $6391 / 5540$ & $\begin{array}{c}255 \text { sarcomas } \\
\text { not more } \\
\text { defined }\end{array}$ & 31 & 21 & [26] \\
\hline
\end{tabular}

R/R: Relapsed or refractory; CNS: Central Nervous System; yrs: years; OS: Osteosarcoma; pt: Patient. * 26 patients have one or more alterations with intermediate or higher priority score; ** in the paper it is reported that 24 patients were considered to have a mutation that was targetable in a clinical trial (12\% matched at level 1 of NCI-Match Criteria in which the gene variant is approved for selection of an approved drug).

PMTs usually consist of three phases. The first phase includes sample collection (especially tumour biopsies), the preparation of biological materials, and the generation of all required genomic data. As a result of these, each tumour of all enrolled patients is univocally associated with a precise molecular profile. During the second phase, genomic data is assessed by an expert multidisciplinary board to evaluate their clinical relevance. This panel of experienced clinicians evaluates the genomic alterations of each tumour considering their biological relevance, their potential therapeutic targeting with available compounds, and their link with the medical history of the patient. These evaluations are necessary for a rapid translation into a clinical decision making. Therefore, whenever possible, the enrolment of the patient into a genomic-driven treatment trial is encouraged.

The second phase aims at identifying the genomic alterations that are relevant for tumour growth and progression that could be selected for a targeted therapy. This clinical research employs computational algorithms able to prioritize the potentially druggable alterations identified from NGS data. In this light, Worst and colleagues developed a work-flow able to rank genomic alterations in seven levels of increasing clinical relevance (e.g., from "very high" to "very low") on the basis of their effect on the encoded protein, the availability of a direct targeting drug, and literature evidences of possible pathway activation [17]. In the INFORM pilot study, patients with a very high priority target alterations (e.g., ALK, BRAF, and NRAS mutations, and MET and NTRK-fusions) showed an improvement in the Progression-Free Survival (PFS) [18]. Indeed, the median PFS in paediatric patients with a high priority genomic alteration treated with the matched drug was significantly higher compared to that of all patients with no druggable aberration (i.e., 204.5 and 114 days, respectively $-p=0.0095$ ) [18]. Hence, a promptly identification 
of patients whose tumours are harbouring a high priority target genomic alteration is necessary to better address the physician's treatment choice.

The preliminary results of the genomic-driven precision medicine trials, despite being promising, also presented us with a two-sided challenge. Firstly, the results showed that feasible access to a genomic program to identify somatic targeted alterations is necessary. This can be achieved with a specialized team to translate the obtained genomic results into reasonable clinical action for those patients [8]. Moreover, the availability of molecular targeted drugs is necessary, especially for more vulnerable populations such as paediatric patients or patients with a rare oncological disease, including OS patients. Recent advances in our understanding of molecular oncogenesis allowed for the stratification of malignancies into molecularly similar tumours, both within and across the tissue of origin, thus leading to the establishment of improved therapeutic treatments [27]. This strongly suggests that the development of targeted therapies can be better informed by tissue agnostic clinical trials, which represent a significant paradigm shift in precision medicine for cancer patients [27].

\section{Osteosarcoma: The Challenges for Successful PMTs}

OS patients represent a minority of patients that have been enrolled into PMTs so far (Table 1). This low enrolment rate is due to some challenges that prevent us from fully exploiting the beneficial impact of PMTs on OS patient quality of life. In the following paragraphs, we will discuss three important hurdles for a successful OS PMTs: (1) The modest incidence rate of this rare tumour [9], (2) the technical issues to manage genomic materials from a difficult tissue of origin (i.e., bone) [8], and (3) the highly heterogenous genomic complexity of OS samples [8,28-30].

\subsection{Osteosarcoma: A Rare Tumour}

OS is a rare tumor and commonly occurs in adolescents and young adults [9]. The genomic landscape of paediatric OS is not distinguishable from genomic features in adult OS. So far, no differences have been found between childhood or adult OS in the frequency of potentially actionable alterations across samples, with respect to altered genes or distinct molecular subsets [8,31]. This could strengthen the collaboration between adult and paediatric oncologists to design aligned targeted-therapy clinical trials and PMTs enlarging OS cohorts.

\subsection{Osteosarcoma: The Technical Issue of Dealing with Bones}

In the last years, the collection of fresh and/or snap-frozen bone sarcoma tissue has been increasingly encouraged in the last years to overcome artefacts from decalcification, and, simultaneously, to foster the genomic characterisation of these tumours in the context of research programs [6]. Nevertheless, the processing of bone sarcoma tissue could be more difficult than expected due to the paucity of material from bone tissue biopsies, thus impacting on the clinical practice management.

\subsection{Osteosarcoma: An Heterogenous Genomic Landscape}

OS has a completely different genomic landscape from other sarcomas that are often characterized by a specific driven aberration, and more broadly by other paediatric cancers $[8,28,29]$. High genomic instability is a hallmark of OS genomics and is especially represented by one subcategory of instability known as chromosomal instability (CIN) [9]. $\mathrm{CIN}$ is the elevated rate of loss or gain sections or entire chromosome resulting in complicated structural, numerical aberration, and wide variability among tumour cells $[8,30,32]$. Consequently, high levels of chromosome structural variations (SV), elevated somatic copy number alterations (SCNA), but also rearrangements resulting from chromothripsis, as well as the hypermutated chromosomal region known as kataegis, are characteristics of OS. All these genomic features result in significant intra- and inter-tumour heterogeneity for OS, with a few recurrent clinically actionable alterations. Moreover, sequencing studies 
showed that OS accumulate non-silent somatic mutations at a rate of $\sim 1.2$ mutations per mega base pairs [33]. All these features are partially in contrast with the genomic landscape of other paediatric cancers that usually present a lower mutational and structural alteration rate [28]. The genomic landscape of OS samples reveals that SCNA have an important role to drive progression of the disease $[8,34,35]$. Nevertheless, the high rate of SCNA and SV made it hard to discriminate driver from passenger alterations, and this could represent an additional obstacle for identifying new molecular targeted therapies for OS [8,36].

The OS heterogenous genomic landscape also includes the immune-genomic features. The promising results of immunotherapy, including immune checkpoint inhibitors, in various cancers, have prompted new clinical trials in sarcomas as well [37]. Nevertheless a promising objective response rate has not been reported for OS patients yet [37].

Recent analyses showed that, globally, OS has a median immune infiltrate level lower than other cancers, with concomitant low T-cell receptor clonalities, whereas revealing a high immune-genomic inter-tumour heterogeneity $[38,39]$. OS can virtually be divided into three subgroups based on the level of immune infiltrate and its activity (i.e., low, intermediate, or high) [39]. Even in tumours with high levels of immune infiltrate, an ineffective immune response may be due to the lack of neoantigens or to the presence of tumour-intrinsic adaptive immune resistance mechanisms that allow for immune evasion or lack of T-cell activation only [39]. However, the identification of OS with high levels of immune infiltrates supports the rationale for developing biomarker-selected approaches to future immunotherapy trials in OS. In addition, it is necessary to explore new targeted therapies that can mitigate immunosuppressive mechanisms [39]. This concept highlights and supports the role of a precision medicine approach for immunotherapy as well.

Up to now, very few case-reports of OS patients treated for druggable genomic alterations have been described (Table 2). Notably, Subbiah et al. reported two patients with relapsed and metastatic osteosarcoma which did not benefit from the targeted therapy of the selected genomic alterations [3]. Drug resistance mechanisms in refractory disease, intra-tumoral heterogeneity, and a possible different genomic profile either between the primary and metastatic sites and the same tumour in different relapses may be responsible for the failure of the targeted therapy. Moreover, most of the alterations identified in OS have at the moment an unpredictable pathogenetic role, thus available target therapies may not act on pathogenic driver aberrations.

Table 2. Case-reports reported in literature of OS patients treated with a matched targeted drug on the basis of their tumour molecular finding.

\begin{tabular}{|c|c|c|c|c|c|c|}
\hline & $\begin{array}{l}\text { Tumour } \\
\text { Histotype }\end{array}$ & Age/Sex & $\begin{array}{l}\text { Actionable Alteration } \\
\text { Considered for } \\
\text { Target-Therapy/Methods }\end{array}$ & Drugs Administered & Response & Ref. \\
\hline Patient 1 & $\begin{array}{l}\text { Metastatic OS } \\
\text { refractory to } \\
\text { 3rd CT line }\end{array}$ & $\begin{array}{c}21 \\
\text { yrs /female }\end{array}$ & $\begin{array}{ll}- & \text { PIK3CA V344G (NGS) } \\
- & \text { c-MET amplification (NGS } \\
& \text { and IHC) }\end{array}$ & $\begin{array}{l}\text { Metformin }+ \\
\text { Rapamycine }+ \\
\text { Crizotinib }\end{array}$ & PD & [3] \\
\hline Patient 2 & $\begin{array}{l}\text { Metastatic OS } \\
\text { refractory to } \\
\text { 4rd CT line }\end{array}$ & $\begin{array}{c}16 \\
\mathrm{yrs} / \mathrm{male}\end{array}$ & $\begin{array}{ll}- & \text { PDGFRA amplification } \\
\text { (NGS and IHC) } \\
\text { - } \quad \text { TP53 loss (NGS) }\end{array}$ & $\begin{array}{c}\text { Sorafenib }+ \\
\text { Bevacizumab }+ \\
\text { Temsirolimus } \\
\text { (Phase I clinical trial } \\
\text { NCT01187199) }\end{array}$ & PD & [3] \\
\hline Patient 3 & $\begin{array}{l}\text { Localized OS } \\
\text { refractory to } \\
\text { 2nd CT line }\end{array}$ & $\begin{array}{c}37 \\
\mathrm{yrs} / \mathrm{male}\end{array}$ & $\begin{array}{ll}\text { - } & \text { Positive staining of } \\
& \text { RANKL (IHC) }\end{array}$ & $\begin{array}{l}\text { Sunitinib + } \\
\text { Denosumab }\end{array}$ & $\begin{array}{l}\text { SD after } 18 \\
\text { months of } \\
\text { treatment }\end{array}$ & [40] \\
\hline Patient 4 & $\begin{array}{l}\text { Localized OS } \\
\text { relapsed after } \\
\text { 1st CT line }\end{array}$ & $\begin{array}{c}50 \\
\mathrm{yrs} / \mathrm{male}\end{array}$ & $\begin{array}{l}\text { - } \quad \text { Strong positive staining for } \\
\text { VEGFR-2 (IHC) }\end{array}$ & Apatinib & $\begin{array}{l}\text { PR at } 11 \text { months } \\
\text { of treatment }\end{array}$ & [41] \\
\hline
\end{tabular}

$\mathrm{CT}$ = chemotherapy; yrs = years; NGS = Next Generation Sequencing; IHC = Immunohistochemistry; PD = Progression Disease; $\mathrm{PR}=$ Partial response; $\mathrm{SD}=$ Stable Disease. 


\section{Target-Specific Clinical Trials for OS Patients}

The role of second, or further-line systemic, therapy for recurrent OS is currently not defined, and there is no international agreement for treatment [6]. To overcome this limitation, wherever possible, OS patient enrolment in prospective studies should be encouraged. The clinical trial landscape for relapsed or advanced OS patients offers a heterogeneous repertoire of treatments that are not uniquely correlated with genomic findings.

Supplementary Table S1 shows the list of clinical trials that are presently active and recruiting relapsed and refractory OS patients, for which the inclusion criteria are clearly defined. The list does not include observational studies or clinical trials without any systemic therapy administration (e.g., surgical studies and radiological studies). The majority are early phase studies: 16 of them $(27 \%)$ are phase I trials, $13(21 \%)$ are phase I/II trials, and $29(49 \%)$ are Phase II trials. Forty $(67 \%)$ studies are designed for young patients including children younger than 12 years. Forty-four of these studies use targeted therapies, and $40 \%$ of them required a specific molecular feature as inclusion criteria (Table 3 ).

Table 3. Main characteristics of the active clinical trial recruiting patients with relapsed/refractory OS.

\begin{tabular}{|c|c|c|}
\hline $\begin{array}{c}\text { CHARACTERISTICS OF THE TRIALS } \\
\text { ( } \mathrm{N}^{\circ} \text { tot: } 60 \text { Clinical Trials Registered on clinicaltrials.gov) }\end{array}$ & $\mathbf{N}$ & $\%$ \\
\hline \multicolumn{3}{|l|}{ INCLUSION CRITERIA } \\
\hline \multicolumn{3}{|l|}{ TUMOUR HISTOLOGY } \\
\hline Only Osteosarcoma & 14 & $23 \%$ \\
\hline Bone Sarcomas & 3 & $5 \%$ \\
\hline All type of sarcomas & 6 & $10 \%$ \\
\hline All solid tumour & 37 & $62 \%$ \\
\hline \multicolumn{3}{|l|}{ AGE OF ENROLLEMENT } \\
\hline$<12$ years & 40 & $67 \%$ \\
\hline$<25$ years & 60 & $100 \%$ \\
\hline \multicolumn{3}{|l|}{ PHASE } \\
\hline I & 16 & $27 \%$ \\
\hline II & 29 & $48 \%$ \\
\hline $\mathrm{I} / \mathrm{II}$ & 13 & $22 \%$ \\
\hline IV & 2 & $3 \%$ \\
\hline \multicolumn{3}{|l|}{ RANDOMIZATION } \\
\hline Yes & 9 & $15 \%$ \\
\hline No & 51 & $85 \%$ \\
\hline \multicolumn{3}{|l|}{ LINE OF THERAPY } \\
\hline 1st line & 5 & $8 \%$ \\
\hline 2nd line and other & 49 & $82 \%$ \\
\hline Maintenance phase & 3 & $5 \%$ \\
\hline All lines of therapy & 3 & $5 \%$ \\
\hline \multicolumn{3}{|l|}{ TYPE OF INVESTIGATIONAL DRUG } \\
\hline Target Therapy & 44 & $73 \%$ \\
\hline Non Target Therapy & 16 & $27 \%$ \\
\hline \multicolumn{3}{|l|}{ TYPE OF TARGET THERAPY } \\
\hline Tyrosine kinase inhibitor & $11^{*}$ & $24 \%$ \\
\hline Monoclonal antibody & $8^{*}$ & $18 \%$ \\
\hline CAR-T & 6 & $13 \%$ \\
\hline CDK inhibitor & 5 & $11 \%$ \\
\hline mTOR inhibitor & 3 & $7 \%$ \\
\hline Combination of two target drugs & 4 & $9 \%$ \\
\hline Others & 8 & $18 \%$ \\
\hline
\end{tabular}


Table 3. Cont.

\begin{tabular}{ccc}
\hline CHARACTERISTICS OF THE TRIALS & $\mathbf{N}$ & $\%$ \\
$\mathbf{~}^{\circ}$ tot: $\mathbf{6 0}$ Clinical Trials Registered on clinicaltrials.gov) & & \\
\hline TARGET THERAPY ASSOCIATED WITH CHEMOTHERAPY & $36 \%$ \\
Yes & 16 & $54 \%$ \\
No & 24 & $9 \%$ \\
CAR-T conditioning regimen & 4 & $70 \%$ \\
REQUESTED TARGET-ALTERATION FOR ENROLLMENT & 42 & $7 \%$ \\
None & 4 & $23 \%$ \\
IHC specific positive staining & 14 & \\
Specific genetic alteration & & \\
AGE OF ENROLLEMENT & $40 \%$ \\
$<12$ years & $53 \%$ \\
$<18$ years & 56 & $100 \%$ \\
\hline 18 years & 60 & $93 \%$ \\
\hline
\end{tabular}

* the study NCT04351308 tests the efficacy of Camrelizumbab versus Apatinib in a randomized fashion. IHC $=$ immunohistochemistry.

The majority includes patients with relapsed or refractory solid tumours; fourteen $(23 \%)$ trials are specifically designed for OS patients. Nine of them use targeted drugs without requiring a documented molecular alteration as inclusion criteria. Regarding the forty-four trials with targeted treatment, $90 \%$ of them have a monotherapy treatment. The most frequent monotherapy treatments are tyrosine-kinase inhibitors (TKIs, 12 trials, $27 \%$ ), followed by monoclonal antibodies ( 8 trials, $18 \%$ ). Four studies use an association treatment strategy with a monoclonal antibody (PD1 or PDL1 inhibitor) and a further target-drug (TKIs or PARP-inhibitor or immunosuppressive drug) (Table 3).

\section{Conclusions}

The translation of genomic findings into clinical oncology continues to grow rapidly, offering novel promising choices of therapy for children and adults with cancer. For those patients presenting druggable genomic alterations these targeted treatments could significantly improve their life span and quality [18].

Over the last decade, the simultaneous advancement of two phenomena has revolutionized the clinical management of patients: (1) The availability of NGS techniques for a rapid identification of genomic aberrations and (2) the development of new target drugs $[8,11,42]$. Therefore, PMTs using clinical molecular testing have become more common for adult malignancies, and more recently for paediatric neoplasms as well [11]. A major challenge presented by PMTs is that the treatment arm is tailored for a small subset of patients with a specific genomic profile, and it is expected to detect a precise feature in a histology agnostic cohort based on a genetic marker [11]. Even if the reported results of the precision medicine approach for oncological diseases are encouraging, there are still obstacles to overcame, especially for histological subtypes such as OS patients.

NGS has allowed us to understand that the heterogenous genomic landscape of OS is completely distinguishable from other sarcoma that are often characterized by a specific driven aberration [29]. Although various pan-cancer genomic trials have described the role of single-nucleotide variants and small focal copy-number alterations in OS biology [35], the widespread somatic copy number alterations (SCNA), chromothripsis, kataegis, and aneuploidy have been clearly described as features of OS, and their role in tumorigenesis remains largely unknown [35]. OS is a heterogenous disease with a high degree of variability in patients [3,9]. For this reason, a major challenge to previous targeted therapies for OS patients has been in the accurate identification of targets within the individual patient [9].

It is widely debated that a biopsy might not be representative of the entire tumour lesion, but multiple and repeated biopsies are sometimes unrealistic for bone sarcomas $[8,35]$. Tumour heterogeneity is a significant issue for cancer genomic research and precision medicine approach, and it is therefore necessary to develop new techniques for a more 
precise analysis (e.g., single-cell analysis) [35]. For instance, traditional transcriptomic analyses are performed on the entire cellular population leading to a difficult identification of the contribution of specific cellular subtypes on the disease progression, thus avoiding the full characterization of intratumoural heterogeneity of OS [43]. Conversely, single-cell RNA sequencing has recently demonstrated promising results in exploring the intra-tumour heterogeneity of various cancers [43]. The current genomic clinical trials could only reflect the average measurements of gene mutation and expression profiling across the tumour cells, omitting the cell type composition, dynamics, and characteristics in OS tumour samples [43]. New solution, such as single-cell approaches, can reveal the wide cellular atlas of malignant cells and tumour micro-environment cell components generally included in each tumour sample. This sequencing solution may optimize the therapeutic target selection and the overall precision medicine approach $[9,43]$.

However, further preclinical and clinical studies are required to evaluate the therapeutic efficacy of these genome targeted pathways [9] and considering alternative treatment schedules using targeted therapies alongside standard treatments throughout all phases of the disease.

The current genomic analysis and PMTs could impact the clinical research of the next future. All data, including genomic findings, toxicity, and efficacy of novel drugs, have a potential implication for optimizing future treatment decisions. Given the rarity and the genomic heterogeneity of OS, a multidisciplinary collaboration is required to fully realize the potential of a precision medicine approach for OS patients. The development process of new drugs and a new therapeutical strategy for OS requires new ways of thinking, improving a rapid identification of patients with a high priority genomic target, considering the use of novel drugs also at an initial phase of a standard treatment, and improving the implementation of nimble statistical design for future clinical trials. Meanwhile, a wide clinical data sharing and harmonization is needed for a comprehensive new drugs longterm toxicity awareness. A novel drug development process must include a strict patient follow-up in order to identify all toxicities (e.g., cardiological, neurological, pneumological issues, fertility, ... ). This clinical monitoring is important to improve the patient quality of life, especially for children and adolescents who receive a novel drug during their growth development period of life.

Supplementary Materials: The following are available online at https://www.mdpi.com/2073 $-4409 / 10 / 2 / 281 / s 1$, Table S1: List of clinical trials that are presently active and recruiting relapsed/refractory OS patients.

Author Contributions: Conceptualization, E.T., A.C., K.M. and M.C.; writing-original draft preparation, E.T., A.C., K.M., S.D.A. and M.C.; writing-review and editing E.T., A.C., K.M. and M.C.; visualization, E.T., A.C. and M.C.; supervision, F.F.; project administration F.F; funding acquisition, M.C. and F.F. All authors have read and agreed to the published version of the manuscript.

Funding: The research leading to these results has received funding from AIRC under MFAG 2017ID. 20566 project-P.I. Cereda Matteo. Funding for open access charge: Italian Association for Cancer Research.

Acknowledgments: The authors acknowledge Lara Statham and Orsola Robasto for assistance with the manuscript and Fondazione Umberto Veronesi.

Conflicts of Interest: The authors declare no conflict of interest.

\section{References}

1. Jafari, F.; Javdansirat, S.; Sanaie, S.; Naseri, A.; Shamekh, A.; Rostamzadeh, D.; Dolati, S. Osteosarcoma: A comprehensive review of management and treatment strategies. Ann. Diagn. Pathol. 2020, 49, 151654. [CrossRef] [PubMed]

2. Bielack, S.S.; Hecker-Nolting, S.; Blattmann, C.; Kager, L. Advances in the management of osteosarcoma. F1000Ressearch 2016, 5, 2767. [CrossRef] [PubMed]

3. Subbiah, V.; Wagner, M.J.; McGuire, M.F.; Sarwari, N.M.; Devarajan, E.; Lewis, V.O.; Westin, S.; Kato, S.; Brown, R.E.; Anderson, P. Personalized comprehensive molecular profiling of high risk osteosarcoma: Implications and limitations for precision medicine. Oncotarget 2015, 6, 40642-40654. [CrossRef] [PubMed] 
4. Tirtei, E.; Asaftei, S.D.; Manicone, R.; Cesari, M.; Paioli, A.; Rocca, M.; Ferrari, S.; Fagioli, F. Survival after second and subsequent recurrences in osteosarcoma: A retrospective multicenter analysis. Tumori 2018, 104, 202-206. [CrossRef]

5. Ferrari, S.; Briccoli, A.; Mercuri, M.; Bertoni, F.; Picci, P.; Tienghi, A.; del Prever, A.B.; Fagioli, F.; Comandone, A.; Bacci, G. Postrelapse survival in osteosarcoma of the extremities: Prognostic factors for long-term survival. J. Clin. Oncol. 2003, 21, 710-715. [CrossRef]

6. Casali, P.G.; Bielack, S.; Abecassis, N.; Aro, H.T.; Bauer, S.; Biagini, R.; Bonvalot, S.; Boukovinas, I.; Bovee, J.V.M.G.; Brennan, B.; et al. Bone sarcomas: ESMO-PaedCan-EURACAN Clinical Practice Guidelines for diagnosis, treatment and follow-up. Ann. Oncol. 2018, 29 (Suppl. 4), iv79-iv95. [CrossRef]

7. Morganti, S.; Tarantino, P.; Ferraro, E.; D’Amico, P.; Duso, B.A.; Curigliano, G. Next Generation Sequencing (NGS): A Revolutionary Technology in Pharmacogenomics and Personalized Medicine in Cancer. Adv. Exp. Med. Biol. 2019, 1168, 9-30. [CrossRef]

8. Tirtei, E.; Cereda, M.; De Luna, E.; Quarello, P.; Asaftei, S.D.; Fagioli, F. Omic approaches to pediatric bone sarcomas. Pediatr. Blood Cancer 2020, 67, e28072. [CrossRef]

9. Zhao, J.; Dean, D.C.; Hornicek, F.J.; Yu, X.; Duan, Z. Emerging next-generation sequencing-based discoveries for targeted osteosarcoma therapy. Cancer Lett. 2020, 474, 158-167. [CrossRef]

10. Parsons, D.W.; Roy, A.; Yang, Y.; Wang, T.; Scollon, S.; Bergstrom, K.; Kerstein, R.A.; Gutierrez, S.; Petersen, A.K.; Bavle, A.; et al. Diagnostic Yield of Clinical Tumor and Germline Whole-Exome Sequencing for Children with Solid Tumors. JAMA Oncol. 2016, 2, 616-624. [CrossRef]

11. Vo, K.T.; Parsons, D.W.; Seibel, N.L. Precision Medicine in Pediatric Oncology. Surg. Oncol. Clin. N. Am. 2020, $29,63-72$. [CrossRef] [PubMed]

12. Heymann, D. Metastatic osteosarcoma challenged by regorafenib. Lancet Oncol. 2019, 20, 12-14. [CrossRef]

13. Egas-Bejar, D.; Anderson, P.M.; Agarwal, R.; Corrales-Medina, F.; Devarajan, E.; Huh, W.W.; Brown, R.E.; Subbiah, V. Theranostic Profiling for Actionable Aberrations in Advanced High Risk Osteosarcoma with Aggressive Biology Reveals High Molecular Diversity: The Human Fingerprint Hypothesis. Oncoscience 2014, 1, 167-179. [CrossRef] [PubMed]

14. Allen, C.E.; Laetsch, T.W.; Mody, R.; Irwin, M.S.; Lim, M.S.; Adamson, P.C.; Seibel, N.L.; Parsons, D.W.; Cho, Y.J.; Janeway, K.; et al. Target and Agent Prioritization for the Children's Oncology Group-National Cancer Institute Pediatric MATCH Trial. J. Natl. Cancer Inst. 2017, 109, djw274. [CrossRef]

15. Coyne, G.O.; Takebe, N.; Chen, A.P. Defining precision: The precision medicine initiative trials NCI-MPACT and NCI-MATCH. Curr. Probl. Cancer 2017, 41, 182-193. [CrossRef] [PubMed]

16. Mody, R.J.; Wu, Y.M.; Lonigro, R.J.; Cao, X.; Roychowdhury, S.; Vats, P.; Frank, K.M.; Prensner, J.R.; Asangani, I.; Palanisamy, N.; et al. Integrative Clinical Sequencing in the Management of Refractory or Relapsed Cancer in Youth. JAMA 2015, 314, 913-925. [CrossRef]

17. Worst, B.C.; van Tilburg, C.M.; Balasubramanian, G.P.; Fiesel, P.; Witt, R.; Freitag, A.; Boudalil, M.; Previti, C.; Wolf, S.; Schmidt, S.; et al. Next-generation personalised medicine for high-risk paediatric cancer patients-The INFORM pilot study. Eur. J. Cancer 2016, 65, 91-101. [CrossRef]

18. Van Tilburg, C.M.; Pfaff, E.; Pajtler, K.W.; Langenberg, K.P.; Fiesel, P.; Jones, B.C.; Balasubramanian, G.P.; Stark, S.; Johann, P.D.; Blattner-Johnson, M. The pediatric precision oncology study INFORM: Clinical outcome and benefit for molecular subgroups. J. Clin. Oncol. 2020, 38 (Suppl. 18), LBA10503. [CrossRef]

19. Harttrampf, A.C.; Lacroix, L.; Deloger, M.; Deschamps, F.; Puget, S.; Auger, N.; Vielh, P.; Varlet, P.; Balogh, Z.; Abbou, S.; et al. Molecular Screening for Cancer Treatment Optimization (MOSCATO-01) in Pediatric Patients: A Single-Institutional Prospective Molecular Stratification Trial. Clin. Cancer Res. 2017, 23, 6101-6112. [CrossRef]

20. Oberg, J.A.; Glade Bender, J.L.; Sulis, M.L.; Pendrick, D.; Sireci, A.N.; Hsiao, S.J.; Turk, A.T.; Dela Cruz, F.S.; Hibshoosh, H.; Remotti, H.; et al. Implementation of next generation sequencing into pediatric hematology-oncology practice: Moving beyond actionable alterations. Genome Med. 2016, 8, 133. [CrossRef]

21. Harris, M.H.; DuBois, S.G.; Glade Bender, J.L.; Kim, A.; Crompton, B.D.; Parker, E.; Dumont, I.P.; Hong, A.L.; Guo, D.; Church, A.; et al. Multicenter Feasibility Study of Tumor Molecular Profiling to Inform Therapeutic Decisions in Advanced Pediatric Solid Tumors: The Individualized Cancer Therapy (iCat) Study. JAMA Oncol. 2016, 2, 608-615. [CrossRef] [PubMed]

22. Chang, W.; Brohl, A.S.; Patidar, R.; Sindiri, S.; Shern, J.F.; Wei, J.S.; Song, Y.K.; Yohe, M.E.; Gryder, B.; Zhang, S.; et al. MultiDimensional ClinOmics for Precision Therapy of Children and Adolescent Young Adults with Relapsed and Refractory Cancer: A Report from the Center for Cancer Research. Clin. Cancer Res. 2016, 22, 3810-3820. [CrossRef] [PubMed]

23. Pincez, T.; Clément, N.; Lapouble, E.; Pierron, G.; Kamal, M.; Bieche, I.; Bernard, V.; Fréneaux, P.; Michon, J.; Orbach, D.; et al. Feasibility and clinical integration of molecular profiling for target identification in pediatric solid tumors. Pediatr. Blood Cancer 2017, 64, e26365. [CrossRef] [PubMed]

24. Khater, F.; Vairy, S.; Langlois, S.; Dumoucel, S.; Sontag, T.; St-Onge, P.; Bittencourt, H.; Dal Soglio, D.; Champagne, J.; Duval, M.; et al. Molecular Profiling of Hard-to-Treat Childhood and Adolescent Cancers. JAMA Netw. Open. 2019, 2, e192906. [CrossRef] [PubMed]

25. Groisberg, R.; Hong, D.S.; Holla, V.; Janku, F.; Piha-Paul, S.; Ravi, V.; Benjamin, R.; Kumar Patel, S.; Somaiah, N.; Conley, A.; et al. Clinical genomic profiling to identify actionable alterations for investigational therapies in patients with diverse sarcomas. Oncotarget 2017, 8, 39254-39267. [CrossRef] [PubMed] 
26. Flaherty, K.T.; Gray, R.J.; Chen, A.P.; Li, S.; McShane, L.M.; Patton, D.; Hamilton, S.R.; Williams, P.M.; Iafrate, A.J.; Sklar, J.; et al. Molecular Landscape and Actionable Alterations in a Genomically Guided Cancer Clinical Trial: National Cancer Institute Molecular Analysis for Therapy Choice (NCI-MATCH). J. Clin. Oncol. 2020, 38, 3883-3894. [CrossRef]

27. Seligson, N.D.; Knepper, T.C.; Ragg, S.; Walko, C.M. Developing Drugs for Tissue-Agnostic Indications: A Paradigm Shift in Leveraging Cancer Biology for Precision Medicine. Clin. Pharmacol. Ther. 2020. [CrossRef]

28. Gröbner, S.N.; Worst, B.C.; Weischenfeldt, J.; Buchhalter, I.; Kleinheinz, K.; Rudneva, V.A.; Johann, P.D.; Balasubramanian, G.P.; Segura-Wang, M.; Brabetz, S.; et al. The landscape of genomic alterations across childhood cancers. Nature 2018, 555, 321-327, Erratum in 2018, 559, E10. [CrossRef]

29. Gianferante, D.M.; Mirabello, L.; Savage, S.A. Germline and somatic genetics of osteosarcoma-Connecting aetiology, biology and therapy. Nat. Rev. Endocrinol. 2017, 13, 480-491. [CrossRef]

30. Lau, C.C.; Taylor, A.; Sun, M.J.Y.; Yu, A.; Shen, J.; Teot, L.; Barkauskus, D.; Krailo, M.; Gorlick, R.; Triche, T.; et al. Genomic Landscape of Osteosarcoma: A Target Report. In Proceedings of the The Connective Tissue Oncology Society (CTOS) Annual Meeting, Tokyo, Japan, 13-16 November 2019. Paper \#01 3329872.

31. Suehara, Y.; Alex, D.; Bowman, A.; Middha, S.; Zehir, A.; Chakravarty, D.; Wang, L.; Jour, G.; Nafa, K.; Hayashi, T.; et al. Clinical Genomic Sequencing of Pediatric and Adult Osteosarcoma Reveals Distinct Molecular Subsets with Potentially Targetable Alterations. Clin. Cancer Res. 2019, 25, 6346-6356. [CrossRef]

32. Martin, J.W.; Squire, J.A.; Zielenska, M. The genetics of osteosarcoma. Sarcoma 2012, 2012, 627254. [CrossRef] [PubMed]

33. Perry, J.A.; Kiezun, A.; Tonzi, P.; Van Allen, E.M.; Carter, S.L.; Baca, S.C.; Cowley, G.S.; Bhatt, A.S.; Rheinbay, E.; Pedamallu, C.S.; et al. Complementary genomic approaches highlight the PI3K/mTOR pathway as a common vulnerability in osteosarcoma. Proc. Natl. Acad. Sci. USA 2014, 111, E5564-E5573. [CrossRef] [PubMed]

34. Sayles, L.C.; Breese, M.R.; Koehne, A.L.; Leung, S.G.; Lee, A.G.; Liu, H.Y.; Spillinger, A.; Shah, A.T.; Tanasa, B.; Straessler, K.; et al. Genome-Informed Targeted Therapy for Osteosarcoma. Cancer Discov. 2019, 9, 46-63. [CrossRef] [PubMed]

35. Roberts, R.D.; Lizardo, M.M.; Reed, D.R.; Hingorani, P.; Glover, J.; Allen-Rhoades, W.; Fan, T.; Khanna, C.; Sweet-Cordero, E.A.; Cash, T.; et al. Provocative questions in osteosarcoma basic and translational biology: A report from the Children's Oncology Group. Cancer 2019, 125, 3514-3525. [CrossRef] [PubMed]

36. Chen, X.; Bahrami, A.; Pappo, A.; Easton, J.; Dalton, J.; Hedlund, E.; Ellison, D.; Shurtleff, S.; Wu, G.; Wei, L.; et al. Recurrent somatic structural variations contribute to tumorigenesis in pediatric osteosarcoma. Cell Rep. 2014, 7, 104-112. [CrossRef]

37. Tawbi, H.A.; Burgess, M.; Bolejack, V.; Van Tine, B.A.; Schuetze, S.M.; Hu, J.; D’Angelo, S.; Attia, S.; Riedel, R.F.; Priebat, D.A.; et al. Pembrolizumab in advanced soft-tissue sarcoma and bone sarcoma (SARC028): A multicentre, two-cohort, single-arm, open-label, phase 2 trial. Lancet Oncol. 2017, 18, 1493-1501, Erratum in 2017, 18, e711. [CrossRef]

38. Keung, E.Z.; Burgess, M.; Salazar, R.; Parra, E.R.; Rodrigues-Canales, J.; Bolejack, V.; Van Tine, B.A.; Schuetze, S.M.; Attia, S.; Riedel, R.F.; et al. Correlative Analyses of the SARC028 Trial Reveal an Association Between Sarcoma-Associated Immune Infiltrate and Response to Pembrolizumab. Clin. Cancer Res. 2020, 26, 1258-1266. [CrossRef]

39. Wu, C.C.; Beird, H.C.; Andrew Livingston, J.; Advani, S.; Mitra, A.; Cao, S.; Reuben, A.; Ingram, D.; Wang, W.L.; Ju, Z.; et al. Immuno-genomic landscape of osteosarcoma. Nat. Commun. 2020, 11, 1008. [CrossRef]

40. Cathomas, R.; Rothermundt, C.; Bode, B.; Fuchs, B.; von Moos, R.; Schwitter, M. RANK ligand blockade with denosumab in combination with sorafenib in chemorefractory osteosarcoma: A possible step forward? Oncology 2015, 88, 257-260. [CrossRef]

41. Zhou, Y.; Zhang, W.; Tang, F.; Luo, Y.; Min, L.; Zhang, W.; Shi, R.; Duan, H.; Tu, C. A case report of apatinib in treating osteosarcoma with pulmonary metastases. Medicine 2017, 96, e6578. [CrossRef]

42. Glade Bender, J.; Verma, A.; Schiffman, J.D. Translating genomic discoveries to the clinic in pediatric oncology. Curr. Opin. Pediatr. 2015, 27, 34-43. [CrossRef] [PubMed]

43. Zhou, Y.; Yang, D.; Yang, Q.; Lv, X.; Huang, W.; Zhou, Z.; Wang, Y.; Zhang, Z.; Yuan, T.; Ding, X.; et al. Single-cell RNA landscape of intratumoral heterogeneity and immunosuppressive microenvironment in advanced osteosarcoma. Nat. Commun. 2020, 11, 6322. [CrossRef] [PubMed] 